\title{
Braslav Field: the prospects for discovering diamondiferous rocks
}

\author{
V.Bordon, V.Astapenko
}

Institute of Geological Sciences of the Academy of Sciences of Belarus; Minsk, Belarus

Joint magnetometric, gravimetric, electrical prospecting, geothermal, geochemical and aerial photographic studies were carried out within the Braslav potentially Kimberlite-bearing field (Belarus) distinguished from aeromagnetic and geological data. About 20 preliminary selected anomalies were investigated, five of which are of obvious interest for prospecting (Soroki, Vasilkishki, Churilovo, etc.). The Soroki anomaly located on the northern side of the same name lake, $9.5 \mathrm{~km}$ south of the settlement of Voropayevo (Postavy district, Vitebsk region) is considered the first site for geological-prospection drilling to be started at.

Detailed magnetometric investigations carried out in the Soroki site have revealed a local magnetic anomaly showing an amplitude about $400 \mathrm{nT}$, an oval shape and the longitudinal axis striking northwestwards. The calculations of DT curve suggest that the anomaly is due to an object occurring at a depth of $380 \mathrm{~m}$ and showing a magnetization of 2,400x106 CGS. A borehole was drilled $9 \mathrm{~km}$ north of the anomaly at the settlement Voropayevo and stripped Devonian deposits at a depth of $100 \mathrm{~m}$ and Upper Proterozoic terrigenous formations at a depth of $380 \mathrm{~m}$. The data available indicate that the crystalline basement occurs there at a depth of $700 \mathrm{~m}$. Magnetic rocks are not found in the sedimentary cover of this region. So, the magnetizing object revealed there may be considered as an explosion pipe related, probably, to the Upper Proterozoic magmatic stage. Gravimetric survey was carried out along the profile running through the centre of the magnetic anomaly and geothermal data were obtained. An asymmetrical gravity anomaly of $1 \mathrm{mGal}$ was recognized within the magnetic anomaly area. Geothermal investigations revealed there a geothermal anomaly that is shown in the temperature decreasing by $0.70 \mathrm{C}$ at a depth of $2.5 \mathrm{~m}$ within a presumable explosion pipe. Some agreements noted in geochemical and geophysical anomalies revealed by different methods confirm the existence of anomalous body in the cover. The geochemical profile coincides with the geothermal one. In each borehole two samples were taken from subsoil sediments (top part of the section) and two samples -- from underlyng deposits (bottom of the borehole). The boundaries of the promising anomaly are well-defined in the profile by a sharp increase of cobalt and nickel concentrations in subsoil sediments and of chromium concentration -- in underlying rocks at a depth of $2.5 \mathrm{~m}$. 